\title{
Structuring Socio-Technical Complexity In Infrastructure Systems: The Biogas System
}

\author{
Reinier Verhoog ${ }^{\mathrm{a}}$ \\ Amineh Ghorbani ${ }^{\mathrm{b}}$ \\ Gerard P.J. Dijkema ${ }^{c}$ \\ Margot P.C. Weijnen ${ }^{b^{*}}$
}

\begin{abstract}
Infrastructure systems consist of many heterogeneous decision making entities and technological artefacts. They are governed through public policy that unravels in a multi-scale institutional context, ranging from norms and values to technical standards. For example, to integrate biogas infrastructure in a region, various forms of governance, laws and regulations need to be implemented. To effectively design these requirements, insights into socio-technical systems can be gained through agent-based modelling and simulation. To implement such social concepts in agent-based models of infrastructure systems, we designed a modelling framework called MAIA, based on the Institutional Analysis and Development framework of Elinor Ostrom. This paper will explain how MAIA can be used to model a biogas energy infrastructure in the Netherlands.
\end{abstract}

\section{Key words: Agent-based modelling; Social simulation; Institutional analysis; Conceptualization.}

\section{Introduction}

Many of the infrastructures that we see today find their origin in simple and often local physical assets, governance, laws and regulation. In the early 20th century, electricity grids in the Netherlands started off as local grids, referred to as islands since they were often not connected, which were governed by the local municipality and Grid Company. As technology advances, infrastructures grow in size and become increasingly interconnected, the robustness of these systems increases but also their complexity. Infrastructure systems are not static, but rather in a state of constant evolution as perceptions and goals of the stakeholders change which are translated to new policies ${ }^{1}$. Policy decisions drive the evolution of the infrastructures, which can be seen to be subject to a constant pressure for change to meet ever shifting perceptions and goals. An example of this is the goal to reduce $\mathrm{CO} 2$ emissions and increase renewable energy production. Centralized fossil based energy infrastructures were not initially designed with these

\footnotetext{
${ }^{a}$ Chair Management of Network Industries, College of Management of Technology, EPFL, CH

${ }^{\mathrm{b}}$ Energy \& Industry group, Faculty of Technology, Policy \& Management, Delft University of Technology, NL.

${ }^{c}$ Chair Energy Systems and Industrial Ecology, Energy and Sustainability Research Institute Groningen, Groningen University, NL

*Corresponding author: Margot Weijnen (weijnen@tudelft.nl) http://dx.doi.org/10.14453/isngi2013.proc.45
} 
goals in mind and are being changed to allow for decentralized renewable energy production for example. It is the continuous interplay between the innovation of the physical infrastructure and the stakeholders through policy and system performance that makes infrastructures complex socio-technical systems.

Agent Based Modelling can be used to model long time periods, just like the popular Equation-Based Models ${ }^{2}$. This is ideal for modelling transitions in systems characterized by a certain degree of inertia and path-dependency as can be expected from (established) infrastructures. To determine whether Agent Based Modelling is a suitable means to model infrastructure systems, van Dam (2009) provides three conditions for complex systems ${ }^{3}$. All three conditions hold for infrastructures:

- Distributed character: stakeholders are interdependent for the realization, operation and utilization of the infrastructures, but are also autonomous in the sense that they can make their own decisions.

- Highly dynamic environment: infrastructure policy and regulation is constantly changing because of shifts in perceptions and goals of stakeholders. Infrastructures are also affected by global trends.

- Interaction flexibility: interaction between stakeholders is not fixed as there are numerous issues that require the attention of multiple stakeholders and there is often not a standard solution.

Any modelling exercise is limited in its focus and level of detail since clear boundaries have to be defined and assumptions have to be made to keep the required efforts within acceptable limits. Therefore, the Agent Based Modelling exercise should be viewed as a process of learning and exploring rather than finding the complete answer ${ }^{4}$.

Apart from learning, conceptual modelling is useful in the process of creating an Agent Based Model. First, conceptual modelling bridges the gap between the real world system and the Agent Based Model, which make it easier and more effective to communicate to others, including those without actual modelling experience. Second, performing the conceptualization step-by-step allows for dialogue between modellers and experts at earlier stages in the process. Third, investing time in conceptualization can result in significant time savings later on in the process. Reaching consensus amongst modelling collaborators as well as unambiguity of the (conceptual) model is important to prevent conflicts and time-consuming model alterations down the road ${ }^{5}$. Finally, because of the richer dialogue and more effective communication, conceptual modelling increases learning.

In this paper MAIA, a meta-model for agent-based modelling of socio-technical systems ${ }^{6}$, will be applied to conceptualize an agent based model of a biogas infrastructure system in the Netherlands and to demonstrate the applicability of MAIA to infrastructure systems. MAIA is useful for modelling infrastructure systems as it not only puts emphasis on the stakeholders and physical artefacts, but also the policies, regulation and governance of the infrastructure system. A static description would not serve much purpose as socio-technical systems are inherently evolutionary due to changing stakeholder perceptions and goals. MAIA provides a clear 
structuring of agent actions which detail the interactions and outcomes necessary to simulate the evolution of an infrastructure system.

While the biogas infrastructure in the Netherlands is small, it is currently developing at a fast rate compared to the natural gas and electricity infrastructure in the Netherlands. Biogas production by water treatments as well as agricultural firms has seen an increase in recent years, as well as the applications of biogas. Biogas is often converted to electricity or upgraded to green gas quality, but it can also be used directly with specialized equipment to replace natural gas. To allow for the production and utilization of biogas in these different applications, the biogas infrastructure is often connected to existing infrastructure, which increases the amount of stakeholders and physical artefacts. Biogas infrastructure is therefore a complex socio-technical system that may exhibit large evolutionary steps in the years ahead.

\section{Modelling Agent Systems Using Institutional Analysis}

MAIA is based on the Institutional Analysis and Development framework (IAD) ${ }^{7}$. MAIA extends and formalizes the IAD concepts to facilitate automatic translation of a systems description to executable software ${ }^{6}$. The MAIA meta-model consists of the following five interrelated structures ${ }^{6}$ :

- Collective structure. Stakeholders are translated into agents by capturing their characteristics and decision criterion based on their perceptions and goals.

- Constitutional structure. Stakeholders can perform multiple roles in infrastructure systems. These roles are formalized in the constitutional structure and have clear rules on who is allowed to perform a certain role. Different roles have different objectives and capabilities, which allows easy modeling of heterogeneous agents who perform similar tasks.

- Physical structure. Physical artefacts are required to produce, convert, transport and consume goods and together make up the physical infrastructure. Stakeholders (agents) own different parts of the physical infrastructure and their assets can either be open to everyone or only accessible to them.

- Operational structure. Stakeholder interactions and decision making are important since they shape the infrastructure system and determine the systems performance. Stakeholders interact in the action arena which consists of several action situations where stakeholders perform actions, affected by the system status over time, powers shift and perceptions change.

- Evaluative structure. Agent interaction and system performance are measured and evaluated. Depending on the perspective of the observer the criteria used to evaluate the infrastructure system under study can vary.

\section{The Biogas Infrastructure}

With an estimated 60PJ in 2030, the theoretical potential for biogas production in the Netherlands is substantial ${ }^{8}$. However, most of the potential is based on the production of biogas by farmers, many of whom are currently struggling to earn back their investments. Subsidies 
play an important role to render the operation of biogas production economically viable in the Netherlands 9 .

Currently, biogas infrastructure and production is relatively small in the Netherlands, but it cannot be seen as an entirely separate infrastructure. Rather, the biogas infrastructure is linked to the electricity infrastructure and to the natural gas infrastructure. This makes biogas an interesting case to study from an institutional point of view, because it brings together the as yet unregulated biogas domain with the electricity and natural gas domains that are subject to extensive regulation.

\section{Modelling the Biogas Infrastructure}

We use the MAIA structures to conceptualize the biogas system. Due to space limitation we will not go into the details of the model here but we will only provide an overview of the concepts for each action situation in the model. The modelling exercise focuses on the production of biogas by water treatments and agricultural firms in the Netherlands and the direct usage of the produced biogas by the consumer.

\section{A. Collaboration Action Situation: finding partners to reduce biogas project costs}

Biogas production and consumption is location dependent because of the transportation and infrastructure costs over longer distances are prohibitive. Economies of scale play an important role in controlling the investment and operation costs of biogas production artefacts. For this reason, farmers defined as agents will attempt to collaborate to share investment costs. The internal decision is simple: if a farmer is interested in biogas production, if its firm is located sufficiently nearby and if the production of biogas is technically feasible for all farmers' firms involved, the farmers will collaborate. Their firms will not merge, as the collaboration only relates to the biogas projects.

\section{B. Biogas contract negotiations action situation: setting a quantity and price for biogas production}

The model focuses on the amount of biogas production as well as the economic performance of biogas producers. Generally, water treatment plants perform well economically as they can produce biogas at a cost as low as $0.037\left[€ / \mathrm{Nm}^{3}\right]^{10}$. The internal decision model for the biogas producer is mainly based on the expected fixed costs and operational costs of biogas production. The internal decision model for the energy consumer is based on the value of natural gas and the reduction of $\mathrm{CO} 2$ emissions by consuming the biogas instead of natural gas. This means that the value of biogas is different for households than it is for large industrial consumers. The agreement is made for a long period of time (at least 12 years) to cover the economic lifetime of the biogas production artefacts.

Once a quantity and price is agreed upon by the producer and consumer (defined as a role in MAIA), it is assumed that all the necessary permits are granted and that the physical artefacts become available for biogas production in the next year. This is a very simplified take on reality, as permits can be a real limitation in some cases when the perception of biogas production is not positive. 


\section{Biogas operation action situation: maximizing operational profit}

The operation of biogas production artefacts is driven by the operational costs and expected profits only. Fixed costs are incurred no matter what the biogas producer does. Water treatment plants have access to a constant and free feedstock, so they will always make an operational profit for the duration of their contracts. Agricultural firms are really dependent on the changes of co-substrate prices, natural gas prices and $\mathrm{CO} 2$ prices. Co-substrate prices are very volatile and can result in large operational losses (or profits) for agricultural firms. Start-up costs of biogas production assets are very high as well, which means that not producing any biogas is often not an option either.

\section{Simulation results}

A The conceptual MAIA model was used to build an agent-based simulation. To build the simulation, data has been collected for different parts of the model. First, the model's performance in terms of agricultural biogas production and balance is very sensitive to the market prices of co-substrate, natural gas and $\mathrm{CO}$. This means that the performance is largely determined by external forces. The model is also sensitive to the write-off period and whether or not prices can be renegotiated during the contracted period. These are negotiation issues that can be determined by the agricultural firms and consumers, therefore these parameters are internal.

Second, it can be observed from figure 1 that the performance of agricultural firms is acceptable to good in almost all 240 scenarios for which the model was run. Risks of individual agricultural firms earning back their investments are shown as the size of the bubbles in figure 1. The risks range from $0 \%$ risk to $3.15 \%$ with an average of $0.92 \%$ over all scenarios.

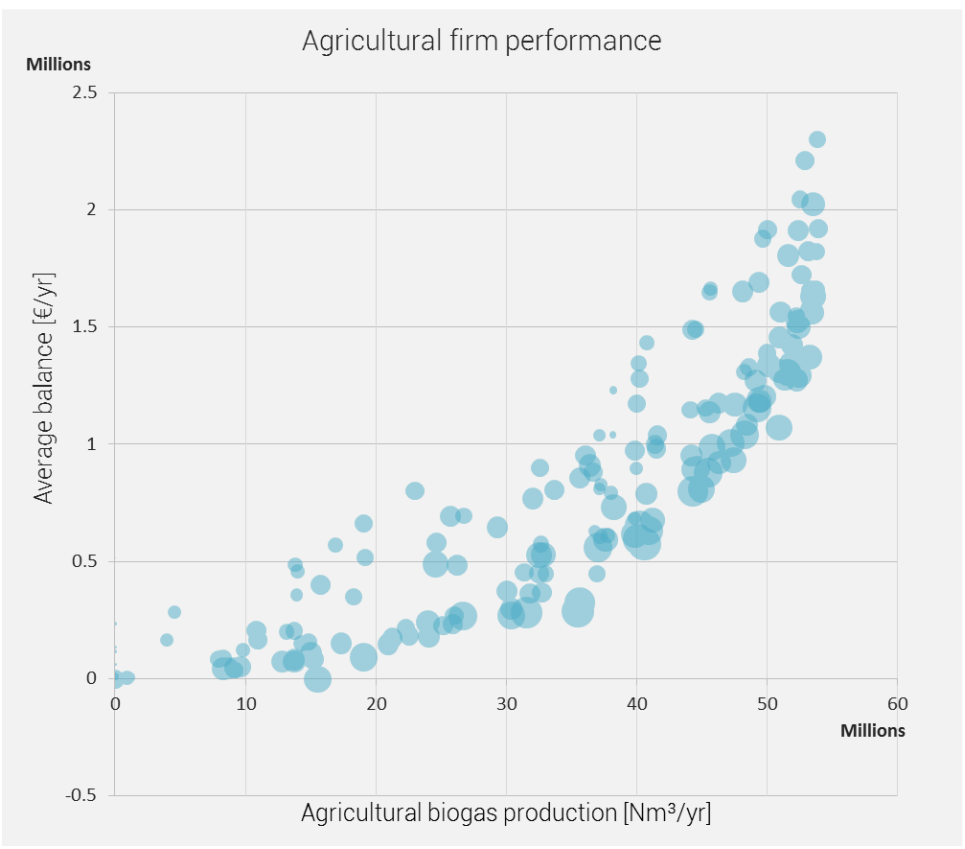

Figure 1. Agricultural firm performance. The size of the bubble indicates the risk of an individual agricultural firm, which ranges from $0 \%$ to $3.15 \%$, with an average of $0.92 \%$ for all 240 scenarios. 
Third, the banana shape indicates that under favourable conditions the agricultural firms do not only produce more biogas but also earn more on the produced biogas. This can be explained by the fact that competition was not directly taken into account in the model in the sense that it could influence the price of biogas.

Fourth, agricultural firms can only compete for the quantity of biogas that is produced, which is limited by the total demand in the simulated area. This explains the asymptote at around 54 million $\left[\mathrm{Nm}^{3} / \mathrm{yr}\right]$.

\section{Conclusion and Future Work}

Conceptualization using MAIA offers sufficient completeness and a sufficient level of detail to allow even modellers without any domain specific knowledge to implement a simulation model. The conceptual model should be created with scientific rigor, for which the five MAIA structures can be used to efficiently gather the required knowledge and data. Special attention should be paid to internal decision models and agent actions at the smallest scale to ensure that the formal description is as close to the simulation model implementation as possible. The online MAIA tool can be used to structure the data in cards and exchange it with other modellers or programmers to extend or implement the model.

The conceptual biogas model has been implemented by different modellers. One model is implemented using NetLogo and the other model is implemented using Agentscape. Both model implementations were solely based on the conceptual biogas model and did not use additional conceptual models. The models have not been compared yet in terms of structure or model output. Future work will focus on the comparison of the two model implementations.

\section{Acknowledgements}

This research has partly been funded by the Next Generation Infrastructures Foundation (http://www.nextgenerationinfrastructures.eu) and Alliander through the NeGoM project.

\section{References}

${ }^{1}$ Chappin, E., and Dijkema, G., "Agent-based modelling of energy infrastructure transitions", International Journal of Critical Infrastructures, Vol. 6, No. 2, 2010, URL: http://inderscience.metapress.com/index/V35568T404JX1LX2.pdf http://dx.doi.org/10.1504/IJCIS.2010.031070

${ }^{2}$ Parunak, H. V. D., Savit, R., and Riolo, R. L., "Agent-based modeling vs. equation-based modeling: A case study and users' guide", in Multi-agent systems and agent-based simulation, Springer Berlin Heidelberg, 1998, pp. 10-25. http://dx.doi.org/10.1007/10692956_2

${ }^{3}$ Dam, K. van., Capturing socio-technical systems with agent-based modelling, Delft University of Technology, 2009.

${ }^{4}$ Dijkema, G., Lukszo, Z., and Weijnen, M., "Introduction", in K. van Dam, I. Nikolic, and Z. Lukszo (Editors), Agent-based modelling of socio-technical systems, Springer, 2012, pp. 1-8. 
International Symposium for Next Generation Infrastructure October 1-4, 2013, Wollongong, Australia

${ }^{5}$ Nikolic, I., Van Dam, K., and Kasmire, J., "Practice", in K. van Dam, I. Nikolic, and Z. Lukszo (Editors), Agent-based modelling of socio-technical systems, Springer, 2012, pp. 73-137.

${ }^{6}$ Ghorbani, A, Bots, P. W. G., Dignum, V., and Dijkema, G. P. J., "Maia: a framework for developing agent-based social simulations", Journal of Artificial Societies and Social Simulation, Vol. 16, No. 2, 2013, pp. 1-19, URL: http://jasss.soc.surrey.ac.uk/16/2/9.html

${ }^{7}$ Ostrom, E., Gardner, R., and Walker, J., Rules, games and common-pool resources. University of Michigan Print, University of Michigan Print, 1994.

${ }^{8}$ Beurskens, L., and Lako, P., Potentieel en rijpheid van hernieuwbare energieopties, Vol. 5, 2010.

${ }^{9}$ Boom, H. van den, Rabobank Food \& Agri Rendement door markt in verdrukking!, 2011, pp. 15.

${ }^{10}$ Lensink, S. M., Wassenaar, J. A., Mozaffarian, M., Luxembourg, S. L., and Faasen, C. J., Basisbedragen in de SDE 2012; Conceptadvies ten behoeve van de marktconsultatie, 2011. 